\title{
Antagonistic Effects of Bacillus cereus Strain B-02 on Morphology, Ultrastructure and Cytophysiology of Botrytis cinerea
}

\author{
FENG-XIA LI, HUI-QUAN MA*, JING LIU AND CHAO ZHANG
}

School of Life Sciences, Shan Dong University of Technology, Zibo 255049, China

Received 22 November 2011, revised 1 March 2012, accepted 6 May 2012

Abstract

\begin{abstract}
The study on antagonistic mechanism of biocontrol strains gives the premise and basis for efficient and stable biological control. This study aimes to overcome of biocontrol agent in aspects of complicated and diversified mode of action, short-lasting and unstable efficacy in the production processes. This study elucidated the antagonistic mechanism of Bacillus cereus strain B-02 on Botrytis cinerea by detecting changes in morphology, ultrastructure and physiology in affected hyphae of Botrytis cinerea. Which provided certain theoretical and practical significance for biological control of gray mould caused by B. cinerea. B. cereus strain B-02 isolated from tomato rhizosphere mightily suppressed gray mold in tomato caused by $B$. cinerea. Spore germination and hyphal growth of B. cinerea were inhibited by $B$. cereus strain B-02. Changes of cell morphology such as distortion, shrinking and swelling were observed by SEM. TEM observation further indicated the ultrastructural alterations of hyphae, including mitochondrion reduction, un-membranous inclusion in cytoplasm, considerable thickening of cell walls, and electronic density enhancement. LSCM observation revealed the fluorescence intensity of nucleus DNA, mitochondrion DNA and reactive oxygen radical in treated hyphae were all stronger than control and the difference was significant $(\mathrm{P}<0.01)$. These results indicated that the antagonistic effects of B. cereus strain B- 02 on B. cinerea were likely due to a combination of abnormal synthesis of nucleus DNA and mitochondrion DNA and multifarious ultrastructural alterations in hyphal cell.
\end{abstract}

Key words: B. cereus, B. cinerea, affected hyphae, antagonistic effect

\section{Introduction}

Gray mould, caused by B. cinerea Pers. Ex. Fr., is a severe and constant threat to field and greenhousesgrown tomatoes in many countries worldwide (Emine et al., 2010). Chemical control has become increasingly difficult due to the development of resistant $B$. cinerea strains as well as the increasing worldwide concern about pesticide use due to environmental problems (Saligkarias et al., 2002; Trotel-Aziz et al., 2008). Biological control using natural antagonistic microorganisms has been extensively studied, and some fungi, and bacteria have been demonstrated to be effective against gray mold (Jae et al., 2006). A great number of reports indicate that certain bacterial strains are beneficial for the growth of plants, these are called plant growthpromoting rhizobacteria (PGPR). An important trait of these bacteria is their ability to maintain a stable relationship with the associated plant species (Smith and Goodman, 1999; Miethling et al., 2000). Microorganisms isolated from the rhizosphere are not only nonexotic, thereby presenting no risk of proliferation of a new microorganism in the environment but also may be better adapted to that plant and therefore provide better control of diseases than organisms originally isolated from other plant species (Trotel-Aziz et al., 2008). Biocontrol bacteria may protect plants against pathogens by bacteriostatic mode and bactericidal mode.

In tomato, much of research reported on the use of the genus Bacillus to control gray mold, mainly including Bacillus subtilis, Bacillus polymyxa, B. cereus, Bacillus megaterium and Bacillus pumilis (Asaka et al., 1996; Kavitha et al., 2005). Some strains of the genus Bacillus have been reported as potential candidates for biological control of fungal pathogens (Dik et al., 1999; Du et al., 2004; Chen et al., 2004; Wang and Yang, 2004; Touré et al.,2004; Qi et al., 2005; Li et al., 2005; Tang et al., 2005; He et al., 2006; Li and Jiang, 2006; Yin et al., 2007). The genus Bacillus depends on a wide variety of traits, such as the production by the strain of various antibiotics and cell wall degrading enzymes (protease, lipase, chitinase, and glucanase) to control pathogen (Tang et al., 2005; Li and Jiang, 2006). Recently, a commercial biofungicide Serenade, which contains

* Corresponding author: H.Q. Ma, No. 12 Zhangzhou Road, Zhangdian, Zibo, Shandong 255049, China; phone: 13864432562; e-mail: mhqswp@sdut.edu.cn 
a Bacillus subtilis strain (QST 713), was reported to be effective against various pathogenic fungi (TrotelAziz et al., 2008). Previous studies reported that the biocontrol bacterium, B. cereus or its metabolite, can inhibit hyphal growth of $B$. cinerea by alterations in the hyphal morphology, and the formation and germination of $B$. cinerea spore. Recent studies have shown that fermentation broth treatment of biocontrol bacteria not only is effective in halting pathogen growth (Pusey and Wilson, 1984; Janisiewicz, 1987; El-Ghaouth et al., 1998; Jijakli and Lepoivre, 1998; Ippolito et al., 2000), but also results in marked morphological changes, structural alterations, and molecular disorganisation of the fungal cells (Roze and Line, 1998; Kamisaka et al., 1999; Wang et al., 2000; Yazgana et al., 2001; Lin and Li, 2003; Hagelina et al., 2004; Mendo et al., 2004; Sun et al., 2005; Xie et al., 2005; Manteca et al., 2005; Leiter et al., 2005). The objectives of this study were to (i) evaluate inhibitory effects of B. cereus strain B-02 on spore germination and hyphal growth of $B$. cinerea; (ii) illustrate ultrastructural alterations occurring in hyphal cells of B. cinerea during interaction with $B$. cereus strain B-02 by scanning electron microscope (SEM) and transmission electron microscope (TEM) to elucidate the biocontrol mechanism; and (iii) visualize the molecular standard of nucleus DNA, mitochondrion DNA and reactive oxygen radical in the affected hyphae of $B$. cinerea by laser scanning confocal microscope (LSCM) to predict the possible target of $B$. cereus strain B-02 on Botrytis cinerea.

\section{Experimental}

\section{Materials and Methods}

Microorganisms. The pathogen B. cinerea used as a cell material for ultrastructural and cytophysiological study was isolated from infected tomato fruit in Zibo, China. The bacterium, B. cereus strain B-02, was originally isolated from the tomato rhizosphere and had very strong inhibitory activity against $B$. cinerea.

Identification of B.cereus strain B-02. B. cereus strain B-02 was identified through the analysis of morphological and biochemical characteristics and $16 \mathrm{~S}$ rDNA sequence in our previous experiment ( $\mathrm{Li}$ et al., 2007). Morphological characteristics of B. cereus strain B-02 were represented after gram staining, spore staining and imaged by Leica TCS-SP2 LSCM. Characteristics of Bacillus from "Bergey's Manual of Determinative Bacteriology" was used to identify the biochemical characteristics of B.cereus strain B-02. Genome DNA of B.cereus strain B-02 was extracted according to $\mathrm{CTAB}$ method and amplified by primers $63 \mathrm{~F}$ and $1494 \mathrm{R}$. B. cereus strain B-02 homology was analyzed in NCBI by $16 \mathrm{~S}$ rDNA sequence. We chose a strain with the strongest inhibitory activity in our isolation experiment by inhibition zone method for the subsequent experiment.

Pretreatment of B. cereus strain B-02 fermentation broth. B. cereus strain B- 02 was inoculated into $50 \mathrm{~mL} \mathrm{LB}$ in a conical flask at $30^{\circ} \mathrm{C}, 140 \mathrm{r} / \mathrm{min}$ for $36 \mathrm{~h}$. The supernatant was filtered by microporous membrane $(0.22 \mu \mathrm{m}, \Phi 25 \mathrm{~mm})$ after centrifuging of B. cereus strain B-02 fermentation broth at $4^{\circ} \mathrm{C}, 8000 \mathrm{r} / \mathrm{min}$ for $10 \mathrm{~min}$. According to cylinder plate method B. cereus strain B-02 filtrate was used to process B. cinerea hyphae in the subsequent experiment. $B$. cinerea grown on PDA supplemented with the same proportion of sterile distilled water was used as a control. Each plate was replicated 3 times.

Preparation of $B$. cinerea hyphal cell and spore suspension. Interactions between B. cinerea and B. cereus strain B-02 were studied by well test. Plates supplemented with B. cereus strain B-02 fermentation broth at $1 \%, 5 \%, 10 \%$ and in the center of the plates inoculated B. cinerea agar disks $(\Phi 6 \mathrm{~mm})$ were allowed to grow at $28^{\circ} \mathrm{C}$ in the dark for $3 \sim 5 \mathrm{~d}$, after which time B. cinerea hyphae grown on PDA were harvested for SEM, TEM and LSCM. For comparisons, controls supplemented with the same proportion of sterile distilled water were harvested from PDA plates with only B. cinerea for SEM, TEM and LSCM visualization, respectively. Each treatment was replicated 3 times and the experiment was repeated twice. B. cinerea spores were removed from 2-week-old PDA culture, and suspended in $5 \mathrm{~mL}$ of sterile distilled water containing $0.05 \%(\mathrm{v} / \mathrm{v})$ Tween 80 . The spore suspension was filtered through 4 layers of sterile cheese cloth to remove adhering hyphae and the concentration was adjusted using a hemocytometer prior to use (Li et al., 2009).

Observation of $B$. cinerea hyphal growth and spore germination. To assess the effects of B. cereus strain B-02 fermentation broth on hyphal growth of $B$. cinerea, $B$. cinerea agar disks $(\Phi 6 \mathrm{~mm})$ was placed in the center of PDA plates containing B. cereus strain B-02 fermentation broth at $1 \%, 5 \%, 10 \%$ at $28^{\circ} \mathrm{C}$ in the dark. Hyphal growth was determined by measuring the colony diameter after $3 \sim 5 \mathrm{~d}$ of inoculation. Controls were supplemented with the same proportion of sterile distilled water. Each treatment was replicated 3 times and the experiment was repeated twice. The effects of $B$. cereus strain B-02 fermentation broth on spore germination of B. cinerea were assessed according to Zhao (2003). Mixture containing $400 \mu \mathrm{L}$ LB fluid medium and $200 \mu \mathrm{L}$ B. cinerea spore suspension was added $200 \mu \mathrm{L}$ B. cereus strain B-02 fermentation broth at original concentration and cultivated at $28^{\circ} \mathrm{C}$ in the dark (Figure 1). The experiment was replicated 3 times. 
SEM specimen preparation and observation. Sample preparation and SEM observation were done as described previously by Chen et al. (2007). Briefly, hyphal samples excised from the 5-day-old culture of B. cinerea treated with sterile distilled water and $10 \%$ B. cereus strain B-02 fermentation broth were fixed in $2.5 \%$ glutaraldehyde at $4^{\circ} \mathrm{C}$ for $2 \mathrm{~h}$, washed in phosphate buffered saline (PBS) for 4 times (15 min each), soaked in $1 \%$ osmium tetroxide at $4^{\circ} \mathrm{C}$ for $2.5 \mathrm{~h}$, dehydrated in a graded ethanol series $(30 \%, 50 \%, 70 \%, 80 \%, 90 \%$, and $100 \%$ ) (10 min each), metathesized in isoamyl acetate for $25 \mathrm{~min}$, hexanenitrile-dried and sputter-coated with gold in vacuum. Micrographs were taken by a Hitachi H-800 SEM. This experiment was repeated 3 times and each treatment was also replicated at least 3 times.

TEM specimen preparation and observation. High-resolution images of hyphal cellular changes in $10 \%$ B. cereus strain B-02 fermentation broth treated samples were obtained by a Hitachi H-800 TEM. Sample preparation was according to Chen et al. (2004). Hyphal samples excised from the 5-day-old culture of B. cinerea were fixed in $3 \%$ glutaraldehyde at $4^{\circ} \mathrm{C}$ for $2 \mathrm{~h}$. The samples were then thoroughly rinsed with 0.1 mol PBS (pH7.2) for 3 times (10 min each), postfixed with osmium tetroxide at $4^{\circ} \mathrm{C}$ for $1 \mathrm{~h}$ and rinsed with PBS again. Samples were then dehydrated in a graded ethanol series (50\%, 70\%, and 90\%) and 100\% acetone for 3 times (10 min each), embedded with Epon 812 and polymerized at $60^{\circ} \mathrm{C}$ for $24 \mathrm{~h}$. Ultra-thin sections ( $80 \mathrm{~nm}$ thickness) were cut with a diamond knife (LKB-V, LKB Company, Sweden) and stained with 2\% uranylacetate for $30 \mathrm{~min}$. Then samples were washed with PBS and sections were stained with lead citrate for $30 \mathrm{~min}$. The control group was treated with the same procedure. This experiment was repeated 3 times and each treatment was also replicated at least 3 times.

LSCM specimen preparation and observation. Hyphal samples excised from the 5-day-old culture of $B$. cinerea treated with B. cereus strain B-02 fermentation broth at $1 \%, 5 \%$ and $10 \%$ were successively stained with $0.1 \%$ AO (Sigma) for $30 \mathrm{~min}, 10 \mu \mathrm{g} / \mathrm{mL}$ Rhodamine 123 for $40 \mathrm{~min}, 5 \mu \mathrm{g} / \mathrm{mL}$ DCFH-DA for $1 \mathrm{~h}$ and rinsed with PBS (pH 7.4) (Kamisaka et al., 1999; Manteca et al., 2005; Leiter et al., 2005). Samples of DNA and reactive oxygen signed were excited by the $488 \mathrm{~nm}$ excitation wavelength with Ar ion laser, the excitation wavelength of samples mitochondrion signed was $514 \mathrm{~nm}$. Hyphae were dealt from the control group by the same method. This experiment was repeated 3 times and each treatment was also replicated at least 3 times. Representative images taken by Leica TCS-SP2 LSCM were presented here. The means and standard deviations of hyphal cellular fluorescence intensity were calculated. T-test was used to analysis the difference between experimental group and control group.

\section{Results}

Identification of $\mathbf{B}$. cereus strain B-02. In this study we isolated five strains in total having inhibitory activity against $B$. cinerea. The inhibitory activity of $B$. cereus strain B-02 was the strongest (Table I). Therefore $B$. cereus strain B-02 was used in the following experiment. Values in Table I like \pm 1.5 mean standard deviation (SD). So are values in Table III. Observation of morphological characteristics revealed that $B$.cereus strain B-02 was rod shape, had flagella, could move, had elliptical heatproof spora, were Gram-positive under the light microscope and LSCM (Fig. 1). The biochemical characteristics of $B$. cereus strain B-02 were described in the Table II. B. cereus strain B-02 was

Table I

Inhibition of the five Bacillus strains on Botrytis cinerea

\begin{tabular}{|l|c|c|}
\hline \multicolumn{1}{|c|}{ Strain } & Inhibition zone $(\mathrm{mm})$ & Inhibitory rate (\%) \\
\hline B-02 & $17.0 \pm 1.5$ & $81.6 \mathrm{a}$ \\
\hline B-04 & $14.0 \pm 2.0$ & $60.9 \mathrm{~b}$ \\
\hline B-01 & $11.0 \pm 1.5$ & $55.2 \mathrm{~b}$ \\
\hline B-07 & $9.0 \pm 2.0$ & $44.1 \mathrm{c}$ \\
\hline B-03 & $6.0 \pm 1.0$ & $43.5 \mathrm{c}$ \\
\hline
\end{tabular}

Note: $\chi^{2}$ test, $5 \%$ significance of difference

Table II

Partial biochemical characteristics of the five Bacillus strains

\begin{tabular}{|l|c|c|c|c|c|}
\hline \multicolumn{1}{|c|}{ Strain } & B-01 & B-02 & B-03 & B-04 & B-07 \\
\hline Shape & rod & rod & rod & rod & rod \\
\hline Spore & + & + & + & + & + \\
\hline Gram staining & + & + & + & + & + \\
\hline Moveability & + & + & + & + & + \\
\hline $15^{\circ}$ C cultivation & + & + & + & + & + \\
\hline $50^{\circ}$ C cultivation & + & + & + & + & + \\
\hline pH5.7 cultivation & + & + & + & + & + \\
\hline Anaerobic cultivation & + & + & + & + & - \\
\hline Catalase & + & + & + & + & + \\
\hline Glucose & ++ & ++ & ++ & ++ & + \\
\hline Sucrose & ++ & ++ & ++ & ++ & + \\
\hline Lactose & - & - & - & - & - \\
\hline Fructose & + & + & + & + & + \\
\hline Xylose & - & - & - & - & + \\
\hline Arabinose & - & - & - & - & + \\
\hline V.P experiment & - & - & - & - & + \\
\hline M.R experiment & + & + & + & + & + \\
\hline Indole experiment & - & - & - & - & - \\
\hline H S experiment & + & + & + & + & ++ \\
\hline Gelatin liquefaction & + & + & + & + & - \\
\hline Amylolysis & + & + & + & + & - \\
\hline
\end{tabular}

Note: + , positive; - , negative 

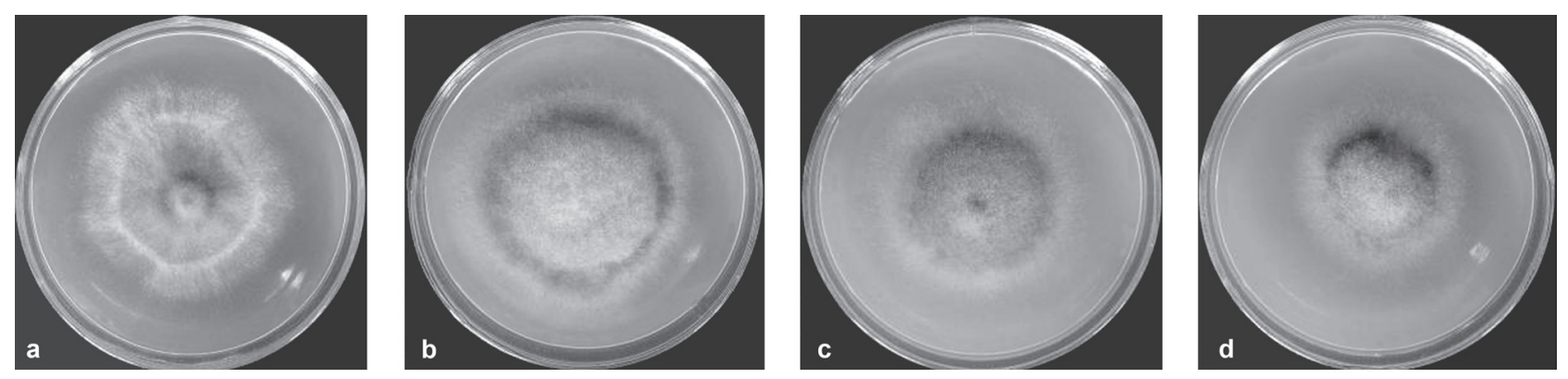

Fig. 1. The comparison of antagonistic activity of Bacillus cereus strain B- 02 fermentation broth $(0.22 \mu \mathrm{m})$ in different dilute multiple (a) control, (b) strain B-02 fermentation broth in dilute multiple of 1:100, (c) strain B-02 fermentation broth in dilute multiple of 1:20, (d) strain B-02 fermentation broth in dilute multiple of 1:10
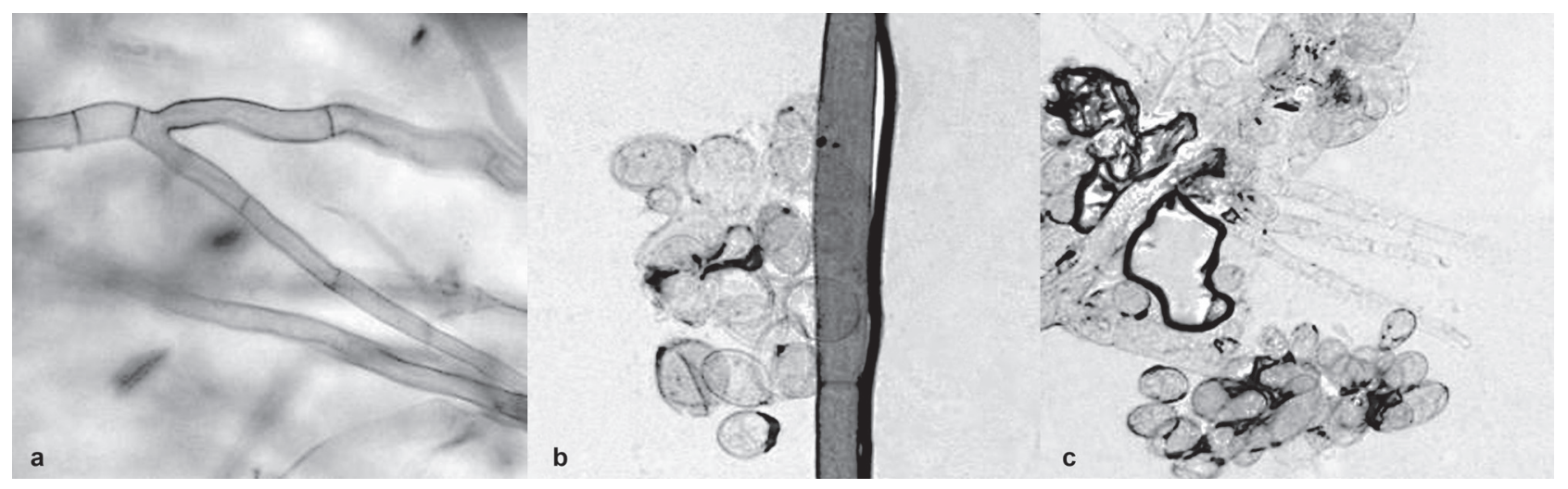

Fig. 2. Effect of Bacillus cereus strain B-02 fermentation broth on the germination of Botrytis cinerea spores

$99 \%$ homologous to B. cereus by $16 \mathrm{~S}$ rDNA sequence analysis. In the evolutionary, the phylogenetic tree of the five strains also indicated that B. cereus strain B-02 closed to B. cereus (Fig. 2). All the evidence, including analysis of morphological characteristics, biochemical characteristics and 16S rDNA sequence, showed that $B$. cereus strain B-02 belonged to B. cereus.

Effects of $B$. cereus strain B-02 fermentation broth on hyphal growth and spore germination of $B$. cinerea. Table III showed that B. cereus strain B-02 fermentation broth at different concentrations inhibited markedly hyphal growth of $B$. cinerea. The inhibitory rate of B. cinerea treated with $10 \%$ B. cereus strain B-02 fermentation broth was up to $33.7 \%$. When B. cereus strain B-02 fermentation broth was diluted to 100 times, its inhibitory action almost disappeared. Fig. 3 showed that the control group, normal hyphal morphology, the rapid speed of hyphal growth, flat and off-white colony, compared with the experimental group. The experimental group was just the reverse. The higher the concentration of B. cereus strain B- 02 fermentation broth was, the heavier the hyphal colour was.

B. cinerea spores untreated with B. cereus strain B-02 fermentation broth germinated normally and B. cinerea hyphae were slim and uniform after $12 \mathrm{~h}$ by the light microscope (Fig. 4a). Even after $48 \mathrm{~h}$ the germination of $B$. cinerea spores was still normal. B. cinerea spores treated with B. cereus strain B-02 fermentation broth germinated partially and the germinal germ tube appeared distorted after $12 \mathrm{~h}$ (Fig. $4 \mathrm{~b}$ and $4 \mathrm{c}$ ).

Table III

Inhibition of Bacillus cereus strain B-02 fermentation broth on Botrytis cinerea

\begin{tabular}{|c|c|c|c|c|c|c|c|c|}
\hline \multirow{2}{*}{$\begin{array}{c}\text { Dilute } \\
\text { multiple }\end{array}$} & \multicolumn{2}{|c|}{$2 \mathrm{~d}$} & \multicolumn{2}{c|}{$3 \mathrm{~d}$} & \multicolumn{2}{c|}{$4 \mathrm{~d}$} & \multicolumn{2}{c|}{$7 \mathrm{~d}$} \\
\cline { 2 - 9 } & MD & IRM & MD & IRM & MD & IRM & MD & IRM \\
\hline 10 & $21.0 \pm 2.2$ & $33.7 \mathrm{a}$ & $33.6 \pm 1.4$ & $28.5 \mathrm{a}$ & $42.6 \pm 0.9$ & $25.3 \mathrm{a}$ & $50.8 \pm 2.7$ & $24.8 \mathrm{a}$ \\
\hline 20 & $23.8 \pm 2.6$ & $21.0 \mathrm{a}$ & $37.0 \pm 3.9$ & $19.7 \mathrm{a}$ & $43.4 \pm 0.8$ & $24.2 \mathrm{a}$ & $53.8 \pm 2.3$ & $19.8 \mathrm{a}$ \\
\hline 100 & $28.1 \pm 1.6$ & $2.2 \mathrm{~b}$ & $44.4 \pm 1.8$ & $0.7 \mathrm{~b}$ & $54.6 \pm 1.1$ & $0.8 \mathrm{~b}$ & $65.3 \pm 1.5$ & $0.42 \mathrm{~b}$ \\
\hline $\mathrm{CK}$ & \multicolumn{3}{|l|}{$28.6 \pm 1.4$} & $44.6 \pm 1.2$ & $55.0 \pm 1.2$ & $65.5 \pm 0.8$ & \\
\hline
\end{tabular}

$\mathrm{MD}(\mathrm{mm})$ : Colony diameter; IRM (\%): Inhibitory rate

Note: $\chi^{2}$ test, $5 \%$ significance of difference 

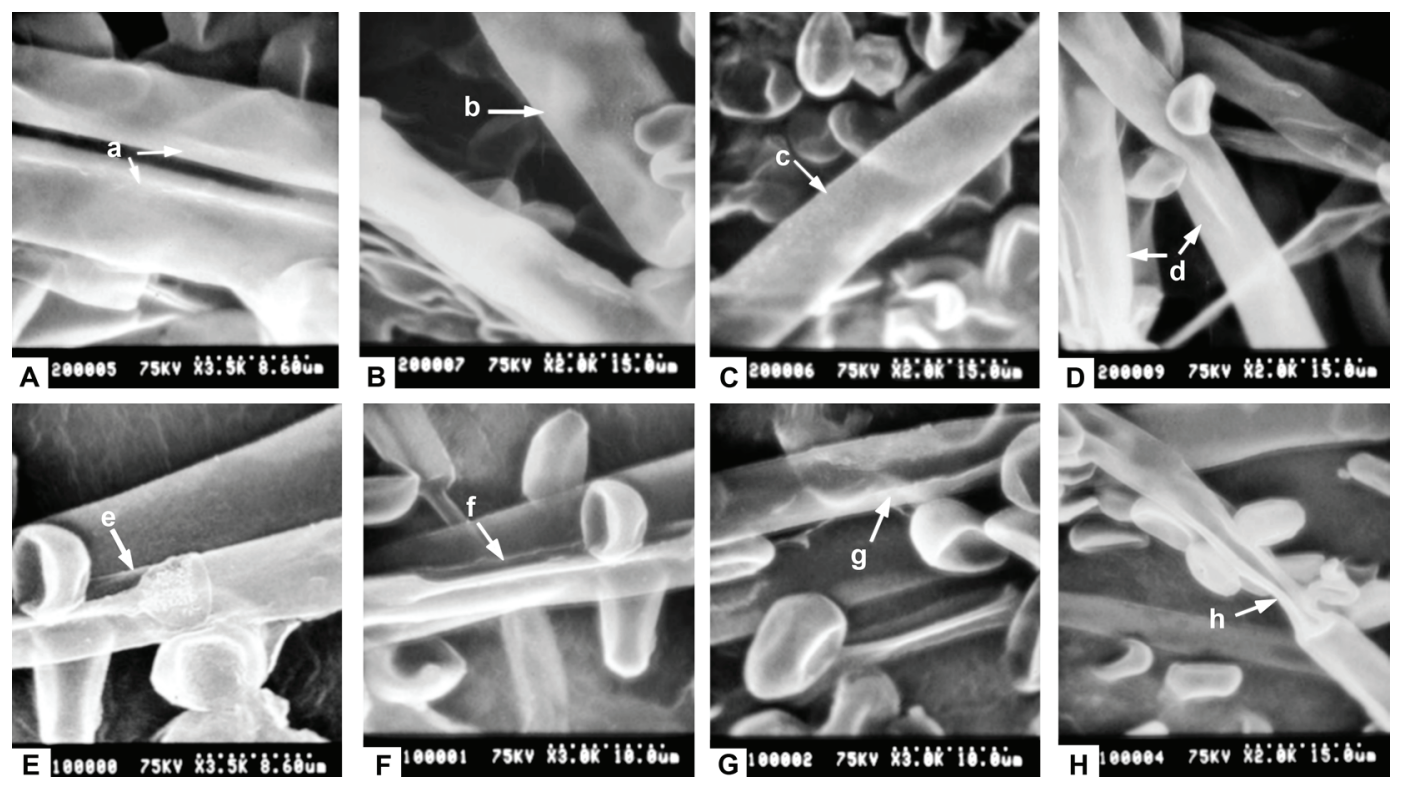

Fig. 3. Scanning electron micrographs of Botrytis cinerea hypha treated and untreated with Bacillus cereus strain B-02 fermentation broth $(\times 5000)$ a, b, c, d: untreated normal hypha (arrows)

e, f, g: strongly destroyed hypha (arrows); h: distorted and collapsed hypha (arrow)

Fig. 4. Untreated hyphal cell configuration of Botrytis cinerea under transmission electron micrographs $(\times 5000)$ A, B: normal cell section M: mitochondrion; N: nucleus; ER: endoplasmic reticulum; CW: cell wall; a: continuous outer surface layer around the hyphal cell wall (CW). Treated hyphal cell configuration of Botrytis cinerea under transmission electron micrographs $(\times 5000)$ C, D, E, F: The treated hyphal cell configuration was destroyed and there was a lot of un-membrane material in cell. M: mitochondrion; $\mathrm{N}$ : nucleus; $\mathrm{C}$ : vacuole; U: un-membrane material; a: continuous outer surface layer around the hyphal cell wall $(\mathrm{CW})$; d: heavily stained material
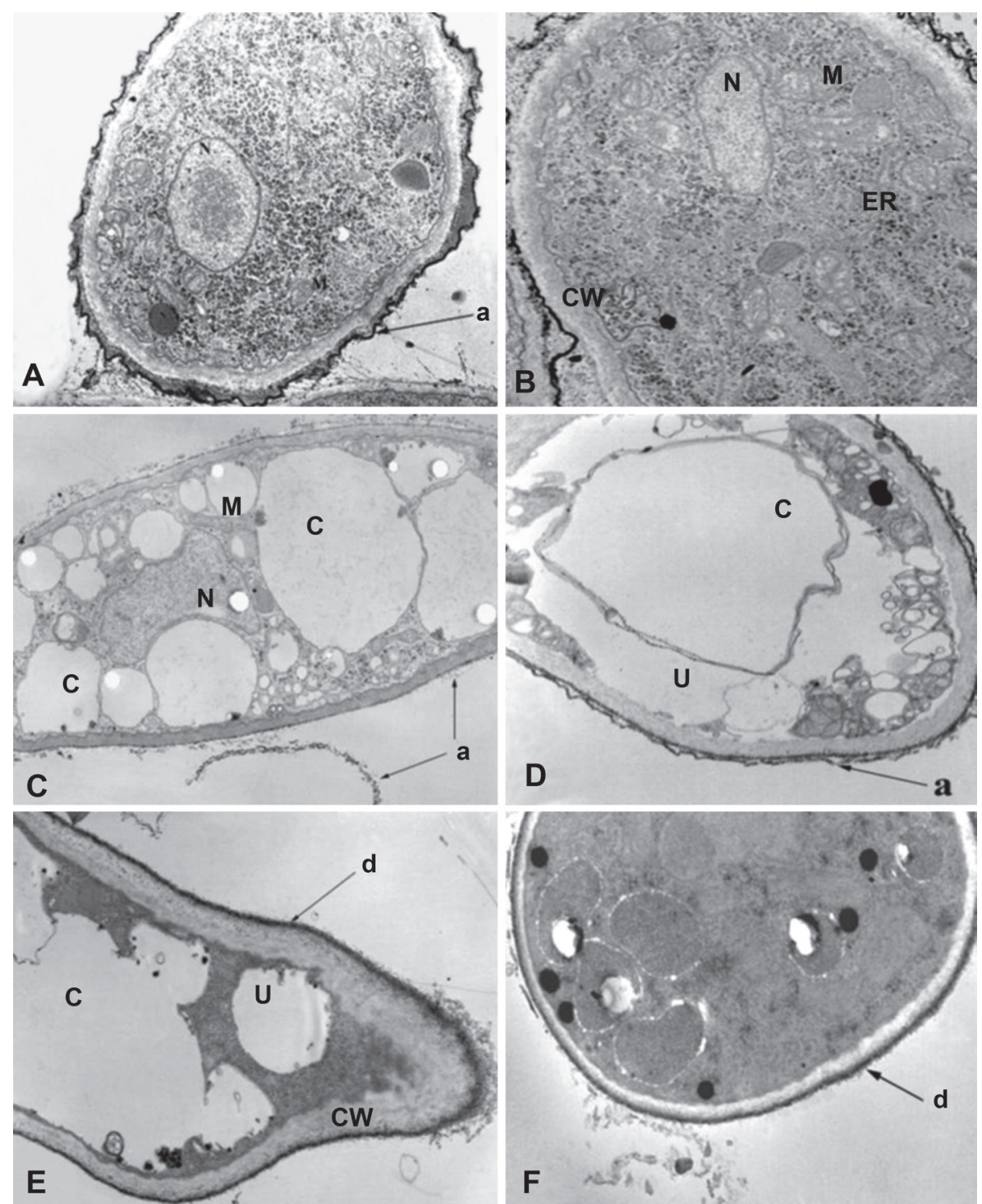

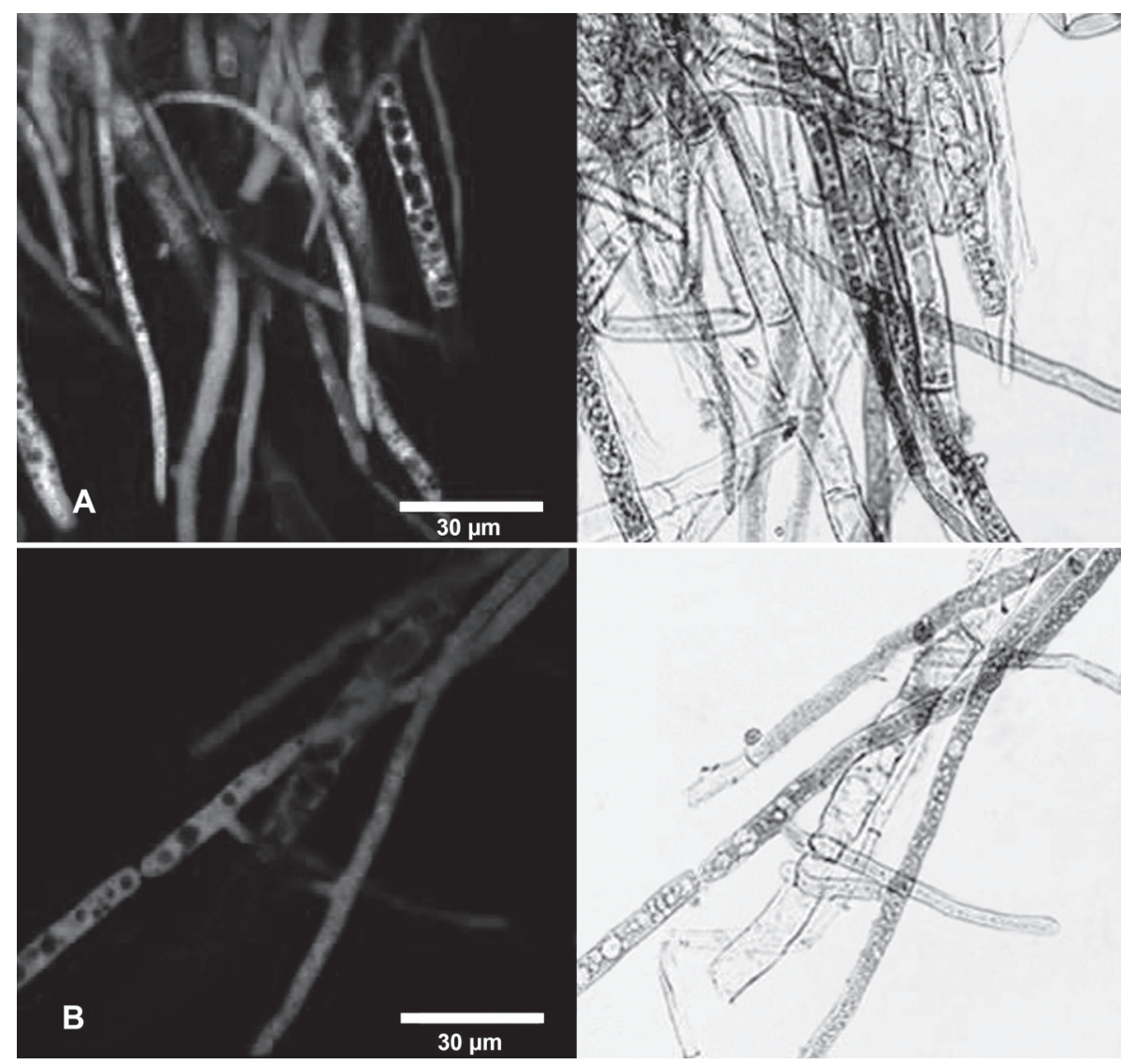

Fig. 5. Laser scanning confocal micrographs (LSCM) of Botrytis cinerea hypha treated and untreated with Bacillus cereus strain B-02 fermentation broth $(\times 1000)$

(A) untreated hyphal cell DNA configuration under LSCM; (B) treated hyphal cell DNA configuration under LSCM. Bars $=30 \mu \mathrm{m}$.
Effects of B. cereus strain B-02 fermentation broth on hyphal ultralstructure of $B$. cinerea. The external features of B. cinerea hyphae untreated with B.cereus strain B-02 fermentation broth were slim, uniform and smooth by the SEM (Fig. 5A, 5B, 5C, and 5D). The treated hyphae were destroyed strongly and the external structures were incomplete (Fig. 5E, 5F, and 5G). Part of the treated hyphae were even distorted, malformed and collapsed (Fig. 5H). The cell nucleus and mitochondrion of the untreated hyphal cell were normal, uniform and clear by the TEM (Fig. 6A and 6B). There was a continuous outer surface layer around the hyphal cell wall and no extravasation outer the hyphal cell wall (Fig. 6A).

Part of the treated hyphal cell mitochondrion disappeared crista and its number decreased. The cell nucleus was not obvious and the unknown un-membranous material appeared in cell (Fig. 6C and 6D). Comparing with the untreated hyphal cell wall (Fig. 6A and 6B), the treated hyphal cell wall was thickened irregularly (Fig. 6E). There was a lot of un-membrane material in cell (Fig. 6D and 6E). Heavily stained material occurred out of the treated hyphal cell wall (Fig. 6E and 6F) and the electronic density of partial treated hyphal cell increased (Fig. 6F).

Effects of $B$. cereus strain B-02 fermentation broth on the hyphal cell DNA content of B. cinerea. The DNA fluorescence intensity of the treated hyphae with B. cereus strain B-02 fermentation broth at dif- ferent concentration was obviously lower than that of the untreated hyphae by LSCM (Fig. 7A and 7B). The fluorescence intensity values of the treated hyphal cell DNA were $80.90 \pm 15.71,109.74 \pm 25.64,119.8 \pm 27.11$ with the different concentration of $B$. cereus strain B-02 fermentation broth $(\times 10, \times 20, \times 100)$, respectively. The fluorescence intensity value of the untreated hyphal cell DNA was $153.89 \pm 24.52$. All the values of experimental group were lower than that of the control group and the difference was significant between the two groups $(\mathrm{P}<0.01)$. The reduction of the treated hyphal cell DNA content showed that the normal synthesis of DNA was disturbed.

Effects of B. cereus strain B-02 fermentation broth on hyphal cell mitochondrial membrane potential of B. cinerea. Comparison of the control group and experimental group showed that the fluorescence intensity of the control group was stronger than that of the experimental group and the control group was more uniform staining than the experimental group by LSCM (Fig. 8A and 8B). The fluorescence intensity values of mitochondrion DNA in the treated hyphal cells were $72.70 \pm 27.03,82.18 \pm 26.49,97.40 \pm 29.89$ with the different concentration of B. cereus strain B-02 fermentation broth $(\times 10, \times 20, \times 100)$, respectively. The fluorescence intensity value of the control group was $108.35 \pm 28.59$ and the difference was significant between the two groups $(\mathrm{P}<0.01)$. So B. cereus strain $\mathrm{B}-02$ fermentation 
Fig. 6. Laser scanning confocal micrographs (LSCM) of Botrytis cinerea hypha treated and untreated with Bacillus cereus strain B-02 fermentation broth $(\times 1000)$

(A) untreated hyphal cell mitochondrion configuration under LSCM; (B) treated hyphal cell mitochondrion configuration under LSCM. Bar, $7.5 \mu \mathrm{m}$
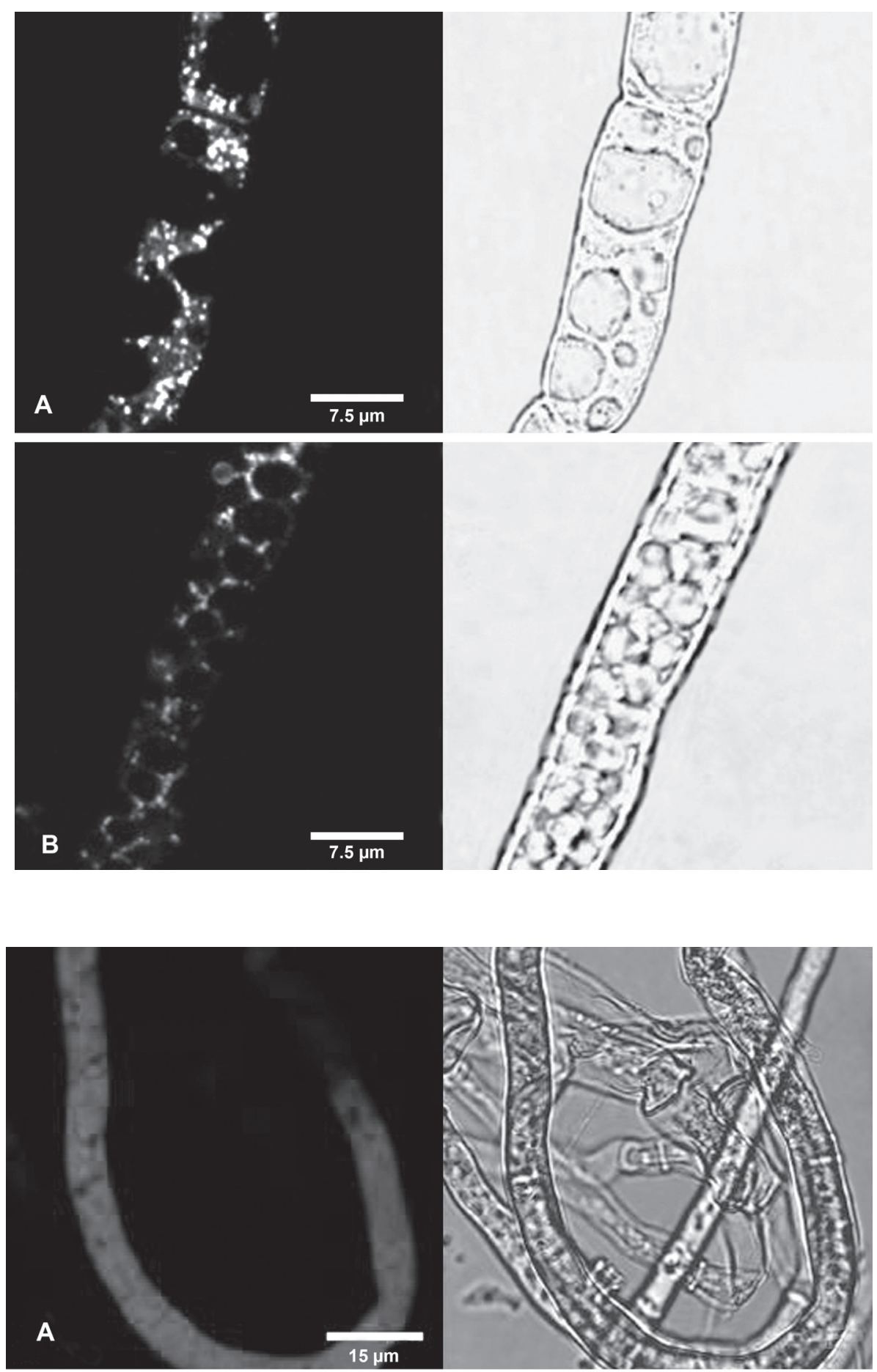

Fig. 7. Laser scanning confocal micrographs (LSCM) of Botrytis cinerea hypha treated and untreated with Bacillus cereus strain B-02 fermentation broth $(\times 1000)$

(A) Fluorescence micrograph of untreated hypha showing reactive oxygen standard (ROS); (B) Fluorescence micrograph of treated hypha showing ROS. Bar, $15 \mu \mathrm{m}$
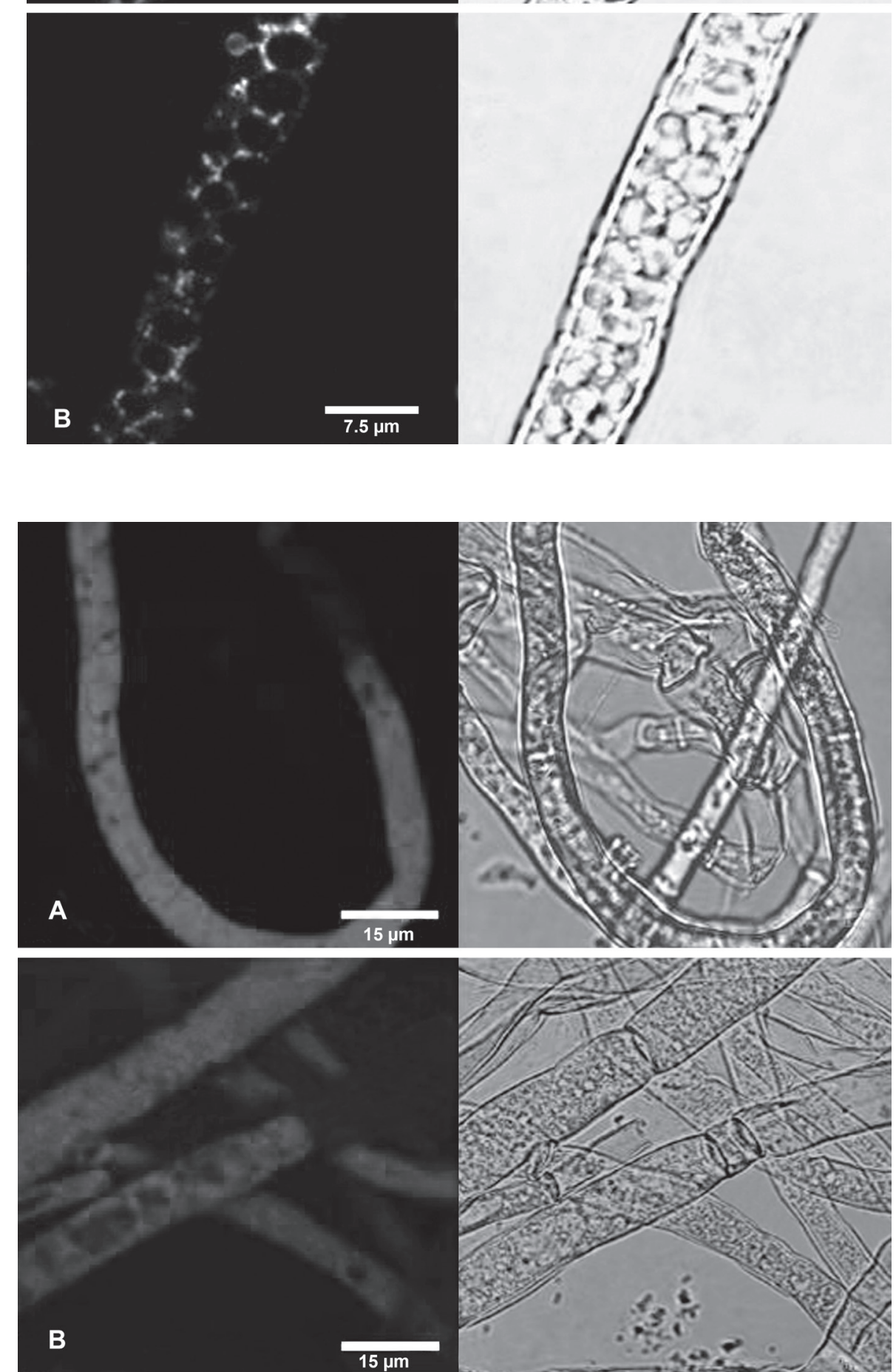
broth could result in the reduction of B. cinerea hyphal cell mitochondrial membrane potential.

Effects of B. cereus strain B-02 fermentation broth on hyphal cell reactive oxygen standard of $B$. cinerea. The fluorescence intensity of the hyphal cell reactive oxygen standard was obviously lower than that of the control group by LSCM (Fig. 9A and 9B). The fluorescence intensity values of the treated hyphae were $44.45 \pm 13.49,50.01 \pm 19.89,53.67 \pm 15.19$ with the different concentration of B. cereus strain B-02 fermentation broth $(\times 10, \times 20, \times 100)$, respectively. The fluorescence intensity value of the control group was $75.42 \pm 17.78$ and the difference was significant between the two groups $(\mathrm{P}<0.01)$. The reason why the hyphal cell reactive oxygen standard of the experimental group was higher than that of the control group was that the hyphal metabolism and its growth speed became slowly caused by the increase of the hyphal cell reactive oxygen standard.

\section{Discussion}

The antagonistic mechanism was studied at the level of cell morphology and cell physiology. Certain concentration of B. cereus strain B-02 fermentation broth resulted in abnormal germination of $B$. cinerea spores and distorted hyphae. The configuration of hyphal cell treated with B. cereus strain B- 02 fermentation broth was destroyed and there were a lot of un-membranous material and vacuoles in cell. Fluorescence intensity of the treated cell and that of the control group was different significantly. Heavily stained material occurred out of the treated hyphal cell wall. We inferred that the membrane permeability of the treated cell was influenced and then the cytoplasm leaked and gathered as a result (Huang et al., 2007). The B. cinerea hyphal cell treated with B. cereus strain B-02 fermentation broth didn't collapse or die directly. The changes of the treated hyphal cell may be a result of indirect effects or comprehensive effects of multiple factors by B. cereus strain B- 02 fermentation broth. The relationship between the effects of the chemical bactericide (e.g. triadimenfon) to hyphal external feature was related to its action mechanism closely. The main action mechanism of chemical bactericide was to make hyphae swollen or distorted, and influence the formation of fungal cell wall (Huang et al., 2007; Chen et al., 2007). It was obvious that the effects of B. cereus strain B-02 fermentation broth on the hyphal feature and ultrastructure were different from that of the chemical bactericide. The treated hyphal cell configuration was changed especially in cell nucleus, mitochondrion, and so on. Which provided morphological basis for the study on antagonistic mechanism of beneficial microorganisms against fungal pathogen.
Mitochondrion, a sensitive organelle in cell, was damaged quite easily and revealed the damaged degree of cell. It was related to the production of oxygen radical and cell apoptosis. The mitochondrion was abnormal, so was the whole cell. Mitochondrial membrane potential, the main part of mitochondrial electrochemistry gradient, reflected the configuration of inner mitochondrial membrane. Mitochondrial membrane potential decrease indicated the configuration of inner mitochondrial membrane was changed and the permeability of it increased (Cortopassi and Wong, 1999). Studies also showed that the descent of mitochondrial membrane potential was one of the important indicators in early cell apoptosis and indicated the cell would access the irreversible process of cell apoptosis. The mitochondrial membrane potential and DNA content in this study decreased markedly. Which indicated B. cereus strain B-02 might cause the alteration of mitochondrial membrane configuration and hyphal cell apoptosis in further.

Reactive oxygen, including superoxide radical, hydrogen peroxide, hydroxy radical, and so on, was one of the main factors inducing cell apoptosis (Shi et al., 2002). Above 95\% reactive oxygen radical from respiratory chain of mitochondrion in our bodies played an important role in cell signal regulation. Nevertheless, excessive reactive oxygen would attack the mitochondrion by oxidation (Factor et al., 2000). The cause and effect relationship between the reactive oxygen and mitochondrion was a common mechanism of cell apoptosis inducing factors. In this study the reactive oxygen standard of treated hyphal cell decreased obviously. Because the normal physiological activity of hyphae was damaged and the reactive oxygen standard measured might be of the damaged hyphae.

From the above, the synthesis of DNA, mitochondrial membrane potential and reactive oxygen quantity of $B$. cinerea hyphae were greatly influenced by B. cereus strain B-02 fermentation broth. So we draw a conclusion that B. cereus strain B-02 against B. cinerea may act on DNA and mitochondrion firstly. Further the physiological and biochemical process of hyphal cell is influenced and even cell apoptosis is induced. Which lead to hyphal growth slowly eventually. HPLC-MS, which would certainly have provided new and interesting information, concerning the presence of bacteriocins, toxins and other metabolites produced by B. cereus in the experimental conditions. What metabolites of $B$. cereus strain B-02 fermentation broth might be responsible for the changes produced. So the chemical analysis of $B$. cereus strain B-02 fermentation broth will be performed on the supernatant met by HPLC-MS in future.

\footnotetext{
Acknowledgements

This work was realised as project supported by Fund of Shandong Natural Sciences, ZR 2011CL006.
} 


\section{Literature}

Asaka O. and M. Shoda. 1996. Biocontrol of Rhizoctonia solani damping-off of tomato with Bacillus subtilis RB-14. Applide and Environmental Microbiology 62: 4081-4085.

Chen L., G.J. Tan and K.J. Ding. 2004. Inhibiting effect of Bacillus subtilis on four Botrytis cinerea. Journal of Fungal Research 2: 44-47. Chen A.L., M.J. Feng and J.T. Feng. 2007. Effects of propamidine on mycelial morphology and ultrastructure of Botrytis cirerea. Scientia Agricultura Sinica 40: 633-637.

Cortopassi G.A. and A. Wong. 1999. Mitochondria in organismal aging and degeneration. Biochimica et Biophysica Acta 1410: 183-193. Du L.X., S.L. Feng and K.Q. Cao. 2004. Study on biological control of B. cinerea by Bacillus subtilis strains BS-208 and BS-209. Chinese Journal of Pesticide Science 6: 37-42.

Dik A.J., G. Koning and J. Köhl. 1999. Evaluation of microbial antagonists for biological control of B. cinerea stem infection in cucumber and tomato. European Journal of Plant Pathology 105: 115-122.

Emine M.S., K. Sener K. and S. Soner. 2010. In vitro and in vivo antifungal activities of the essential oils of various plants against tomato grey mould disease agent Botrytis cinerea. International Journal of Food Microbiology 143: 183-189.

El-Ghaouth A., C.L. Wilson and M.Wisniewski. 1998. Ultrastructural and cytochemical aspects of the biological control of $B$. cinerea by Candida saitoana in apple fruit. Biological Control 88: 283-291. Factor V.M., D. Laskowska and M.R. Jensen, J.T. Woitach, N.C. Popescu and S.S. Thorgeirsson. 2000. Vitamin E reduces chromosomal damage and inhibits hepatic tumor formation in a transgenic mouse model. Proceedings of the National Academy of Sciences of the United States of America 97: 2196-2201.

He Y.J., H.M. Liu and H.B. Hu. 2006. Isolation and characterization of a new Pseudomonas strain against Phytophthora capsici. Acta Microbiologica Sinica 46: 516-521.

Huang L.L., Z.S. Kang and Q.M. Han. 2007. Effects of fungicide triadimefon on development of Curvularia lunata in vitro. Mycosystema 26: 226-233.

Han Q.M., Z.S. Kang, L.L. Huang and J. Zhao. 2005. Cytological studies of effects of tebuconazole on infection process of Fusarium graminearum on wheat spikes. Acta Phytopathologica Sinica 32: $57-62$.

Hagelina G., I. Ouliea and Å. Raknesa. 2004. Preparative highperformance liquid chromatographic separation and analysis of the Maltacine complex - a family of cyclic peptide antibiotics from Bacillus subtilis. Journal of Chromatography B 811: 243-251.

Ippolito A., A. El-Ghaouth and C.L. Wilson. 2000. Control of postharvest decay of apple fruit by Aureobasidium pullulans and induction of defense responses. Postharvest Biology and Technolog. 19: 265-272.

Jae P.L., L. Seon-Woo, S.K. Choul, H.S. Ji, H.S. Ju, Y.L. Kwang, J.K. Hyun, J.J. Soon and J.M. Byung. 2006. Evaluation of formulations of Bacillus licheniformis for the biological control of tomato gray mold caused by Botrytis cinerea. Biological Control 37: 329-337. Janisiewicz W.J. 1987. Postharvest biological control of blue mold on apples. Phytopathology 77: 481-485.

Jijakli M.H. and P. Lepoivre. 1998. Characterization of an exo1,3-glucanase produced by Pichia anomala strain antagonist of B. cinerea on apples. Biological Control 88: 335-343.

Kavitha S., S. Senthilkumar, S. Gnanamanickam, I. Mohammed, and J. Rajadas. 2005. Isolation and partial characterization of antifungal protein from Bacillus polymyxa strain VLB16. Process Biochemistry 40: 3236-3243.

Kamisaka Y., N. Noda and T. Sakai. 1999. Lipid bodies and lipid body formation in an oleaginous fungus, Mortierella ramanniana var. angulispora. Biochimica et Biophysica Acta 1438: 185-198.
Li H.B., J. Peng and Y. Bao. 2005. Preliminary studies on isolation and screening of Fluorescent Pseudomonas spp. for biocontrol sclerotinia sclerotiorum. Chinese Agricultural Science Bulletin 21: 334-337. Li W.J. and R.B. Jiang. 2006. The isolation and characteristic analysis of antagonistic substances produced by Brevibacillus laterosporus X10. Journal of Biology 23: 16-19.

Leiter E., H. Szappanos and C. Oberparleiter. 2005. Antifungal protein PAF severely affects the integrity of the plasma membrane of Aspergillus nidulans and induces an apoptosis-like phenotype. Antimicrob Agents Chemother 49: 2445-53.

Lin F.C. and D.B. Li. 2003. Cell-lyric effect of Bacillus subtilis on plant fungal pathogens; Acta Phytopathologica Sinica 33: 174-177. Li G.X., H.Q. Ma, J. Liu and J. Dong. 2007. Identification and inhibitory research of antagonistic bacteria against Botrytis cinerea. Shandong Agricultural Sciences 2: 69-72.

Li Y.C., X.J. Sun, Y. Bi, Y.H. Ge and Y. Wang. 2009. Antifungal activity of chitosan on Fusarium sulphureum in relation to dry rot of potato tuber. Agricultural Sciences in China 8: 597-604.

Li Y., X.P. Zhang and K.Q. Zhang. 2005. Optimization of Conditions on Submerged Fermentation of B. cereus. Microbiology 32: 45-49.

Liu J.G., Y. Pei, W. Cong and Y.F. Ou. 2001. Studies on fermentation conditions of B. cereus strain S1. Industrial Microbiology 31: 4-7. Miethling R., G. Wieland, H. Backhaus and C.C. Tebbe. 2000. Variation of microbial rhizosphere communities in response to crop species, soil origin, and inoculation with Sinorhizobium melilotiL33. Microb Ecol. 40: 43-56.

Manteca Á., M. Fernández and J. Sánchez. 2005. A death round affecting a young compartmentalized mycelium precedes aerial mycelium dismantling in confluent surface cultures of Streptomyces antibioticus. Microbiology 151: 3689-3697.

Mendo S., N.A. Faustino and A.C. Sarmento. 2004. Purification and characterization of a new peptide antibiotic produced by a thermotolerant Bacillus licheniformis strain. Biotechnology Letters 26: 115-119.

Pusey P.L. and C.L. Wilson. 1984. Postharvest biological control of stone fruit brown rot by Bacillus subtilis. Plant Disease 68: 753-756. Qi D.M., M. Hui and Q.M. Liang. 2005. Postharvest Biological Control of Blue Mold and Black Spot on Appale-Pear (Pyrus Brestschneideri Rehd) Fruit by Bacillus Subtilis H110. Chinese Journal of Applied and Environmental Biology 11: 171-174.

Roze L.V. and J.E. Line. 1998. Lovastain triggers an apoptosis-like cell death process in the fungus Mucor racemosus. Fnugal Genet Biol. 25: 119-133.

Saligkarias I.D., F.T. Gravanis and H.A.S. Epton. 2002. Biological control of B. cinerea on tomato plants by the use of epiphytic yeasts Candida guilliermondii strains 101 and US 7 and Candida oleophila strain I-182:I.in vivo studies. Biological Control. 25: 143-150.

Smith K.P. and R.M. Goodman. 1999. Host variation for interactions with beneficial plant-associated microbes; Annu Rev Phytopathol. 37: 473-491.

Shi G.P., H.X. Du and Z.W. Liu. 2002. Effects of Hydrogen Peroxide on Producing Intracellular ROS of WB-344 Rat Liver Epithelial Cell. Acta Biophysica Sinica 18: 462-466.

Tang L.J., Z.L. Ji and J.Y. Xu. 2005. Mechanisms of action to B. cinerea and antimicrobial substance of Bacillus licheniformis W10. Chinese Journal of Biological Control. 21: 203-205.

Touré Y., M. Ongena and P. Jacques. 2004. Role of lipopeptides produced by Bacillus subtilis GA1 in the reduction of grey mould disease caused by B. cinerea on apple. Journal of Applied Microbiology 96: 1151-1160.

Trotel-Aziz P., M. Conderchet, S. Biagianti and A. Aziz. 2008. Characterization of new bacterial biocontrol agents Acinetobacter, Bacillus, Pantoea and Pseudomonas spp. mediating grapevine resistance against Botrytis cinerea. Environmental and Experimental Botany 64: 21-32. 
Wang G. and Z.W. Yang. 2004. Inhibitory action of Pseudomonas fluorescens P2-5 strain to Gaeumannomyces graminis var.tritici; Plant Protection 30: 32-34.

Wan D.H., Z.J. Wu and Deng Y.L. 2006. Factors Affecting Production of Antagonistic Substance by Bacillus subtilis B75, a Potential Biocontrol Agent against Tobacco Brown Spot; Chinese Journal of Biological Control. 22: 244-247.

Wang L.D., Guo D.A. and Yuan L. 2000. Antifungal effect of Three Natural Products on the Genetic Substance of Saccharomyces Cerevisiaegl and Pototheca Wckerhamii. Acta Phytopathologica Sinica 35: 860-863.

Xie X.M., K. Long and Y. Xu. 2005. Effect of cinnamaldehyde and citral on DNA and RNA in Aspergillus flavus and A. fumigatus cells. Chinese Traditional and Herbal Drugs. 36: 558-560.
Yin J.F., W.H. Zhang and J.Q. Li. 2007. Screening and antagonistic mechanism of biocontrol agents against pepper Phytophthora blight. Acta Phytopathologica Sinica 37: 88-94.

Yazgana A., G. Özcengiza and E. Özcengizb. 2001. Bacilysin biosynthesis by a partially-purified enzyme fraction from Bacillus subtilis. Enzyme and Microbial Technology 29: 400-406.

Zhao D.L., L.Z. Zeng and H. Li. 2006. Fermentation of Bacillus polymyxa JW-725 and preliminary extraction of the antifungal substances. Plant Protection 32: 47-50.

Zhao J.H. 2003. The study of the biocontrol activity against B. cinerea by Bacillus subtilis 728 isolated from marine environment. Doctoral Dissertation. 